\title{
Hybrid Search Optimization Algorithms for the Security Constrained Unit Commitment Solution
}

\author{
J. Mahil, A. Anto Spiritus Kingsly, Satyanarayana Addala
}

\begin{abstract}
The effect of a lot of wind has convoluted ramifications to Unit Commitment (UC) and Economic Dispatch (ED). The Security Constrained Unit Commitment (SCUC) is utilized to acquire a UC with the base expense and framework's security. Ordinarily, the SCUC's limitations incorporate the heap balance, the hold prerequisite, slope rate limits, minimum up and down time limits and network constraints. In this paper, Memetic Algorithm (MM) algorithm based Prediction Intervals (PIs) are executed utilizing hybrid Particle Swarm Optimization and Gravitational Search Algorithm (PSOGSA) based Lower-Upper Bound Estimation (LUBE) technique for wind power conjecture vulnerability evaluation. At that point the wind control situations are fused into a SCUC model. Hybrid MM-Bee Colony algorithm is utilized to take care of the stochastic SCUC issue.
\end{abstract}

Keywords - Decision making, Particle Swarm Optimization and Gravitational Search Algorithm, Bee Colony algorithm, Prediction Interval, Memetic Algorithm.

\section{INTRODUCTION}

The inherent intermittency and variability of renewable generation requires prominent changes in the current industry practices to maintain the reliability and the efficient operation system. Unit Commitment (UC) and conventional generation units are used to obtain the solution for variability and limited predictability to compensate. In C.P. Cheng et al. [1] Lagrangian Relaxation and Genetic Algorithms (LRGA) technique is utilized to refresh the lagrangian multipliers and improve the presentation of LR strategy in taking care of combinatorial streamlining issues, for example, the UC issue. HaoQuan et al. [2] built up the nonparametric NN based expectation interims (PIs) for figure vulnerability evaluation. Jiang et al.

Revised Manuscript Received on August 30, 2019.

* Correspondence Author

J. Mahil*, Professor, Dept. of Electrical and Electronics Engineering, Swarnandhra College of Engineering and Technology, Narsapur, Andhra Pradesh, India.

A. Anto Spiritus Kingsly, Professor, Dept. of Electronics and Communication Engineering, Swarnandhra College of Engineering and Technology, Narsapur, Andhra Pradesh, India.

Satyanarayana Addala, Assistant Professor, Dept. of Electrical and Electronics Engineering, Swarnandhra College of Engineering and Technology, Narsapur, Andhra Pradesh, India.

(c) The Authors. Published by Blue Eyes Intelligence Engineering and Sciences Publication (BEIESP). This is an open access article under the CC BY-NC-ND license (http://creativecommons.org/licenses/by-nc-nd/4.0/)
[3] built up a hearty enhancement way to deal with oblige wind yield vulnerability with the target of giving a vigorous unit duty plan for the warm generators in the day-ahead market that limits the complete expense under the most noticeably terrible breeze power yield situation. Kazarlis et al. [4] built up a GA based answer for the UC issue. Utilizing the changing quality capacity method and including issue explicit administrators, agreeable answers for the unit duty issue are acquired. Logenthiran and Srinivasan [5] created PSO based heuristic streamlining calculations to take care of the UC issue. This PSO calculation is for sure fit for acquiring higher quality arrangements proficiently in taking care of UC issues. Srinivasan and Chazelas [6] built up an Evolutionary Algorithm (EA) with issue explicit heuristics and geneticoperators are utilized to take care of the issue.

Sturt and Strbac [7] described an efficient formulation of the SUC problem that is designed for use in scheduling simulations of single bus power systems. Swarup and Yamashiro [8] developed the solution methodology of UC using GA. The minimum up and down time constraints, startup cost and spinning reserve as considered for problem formulation. Ummels et al. [9] described simulation method that can fully assess the impacts of large-scale wind power on system operations from cost, reliability, and environmental perspectives. Wang et al. [10] developed a SCUC algorithm which takes into account the intermittency and volatility of wind power generation. Tripathy et al. [11] developed the method to predict the weather condition by Artificial Neural Network and Particle Swarm Optimization Technique. A. Khosravi et al. [12] evaluated the four leading techniques for construction of PIs for neural network point forecasts. The delta, Bayesian, bootstrap, and Mean-Variance Estimation (MVE) methods are evaluated and their performance for generating high-quality PIs is compared.

X.Y Ma et al. [13] describe the forecast error via observational dispersions forecast bins and assumes that wind power fluctuations over unit interval follow t area scale distribution. W. Ongsakul and N. Petcharaks [14] developed an Enhanced adaptive Lagrangian Relaxation (ELR) for a UC problem. ELR consists of Adaptive LR (ALR) and heuristic search.. Sree Renga Raja et al. [16] developed Cascade Correlation algorithm based on ANN for economic load dispatch and economic emission dispatch to obtain optimal fuel cost and optimal emission of generating units, respectively. 
T. Vigneswari and M. A. Maluk Mohamed [17] developed Artificial Bee Colony (ABC) algorithm for optimal job scheduling problem based on foraging behaviour of bees. $\mathrm{K}$. Zielinski and R. Laur [18] described PSO method for the optimization of the constrained test suite of the special session on constrained real parameter optimization at CEC06. The UC problem is solved in the master problem with the forecasted intermittent wind power generation.

\section{METHODOLOGY}

PIs are integral tools to deal with vulnerabilities related with point estimates. The fundamental thought of LUBE technique is to utilize a Memetic algorithm with two yields to legitimately create the upper and lower limits of PIs.

$$
\begin{aligned}
y_{i}=f_{1}\left(\sum _ { j = 1 } ^ { N _ { \mathrm { n } } } \left(w_{i j} f_{2}\left(\sum_{k=1}^{N_{i}} v_{j k} x_{k}+b_{v j}\right)\right.\right. \\
\left.\left.+b_{w i}\right)\right), \\
i=1,2, \ldots N_{0}
\end{aligned}
$$

Particle Swarm Optimization and Gravitational Search Algorithm based LUBE strategy is connected to make estimates for a rundown of PIs with consistent degrees of 5\%-95\%.All the anticipated and estimated wind power esteems are standardized by the limit of the wind ranch. In the event that the gauge mistakes are thought to be symmetrically circulated, at that point every PI has to be reduced. The lower and upper limits relate to the $(\alpha / 2) \%$ and $(1-\alpha / 2) \%$ are the two exceptionally deteriorated quantities of $(1-\alpha) \%$ PIs. Fig 1 demonstrates flowchart of the ANN preparing utilizing Particle Swarm Optimization and Gravitational Search Algorithm.

After the ECDF curve fitting, Monte Carlo reproduction is connected to create situations from the empirical cumulative distribution function (ECDF) and for every situation, an arbitrary number somewhere in the range of 0 and 1 is consistently produced. The comparing wind control on the ECDF bend is the breeze power yield at this situation. The proposed technique additionally fabricates a significant scaffold among the PIs and the situations utilized in the stochastic model. The reason for the proposed strategy is to produce the situations from a rundown of PIs. These produced situations are included into the stochastic computational models for basic leadership and hazard evaluation.

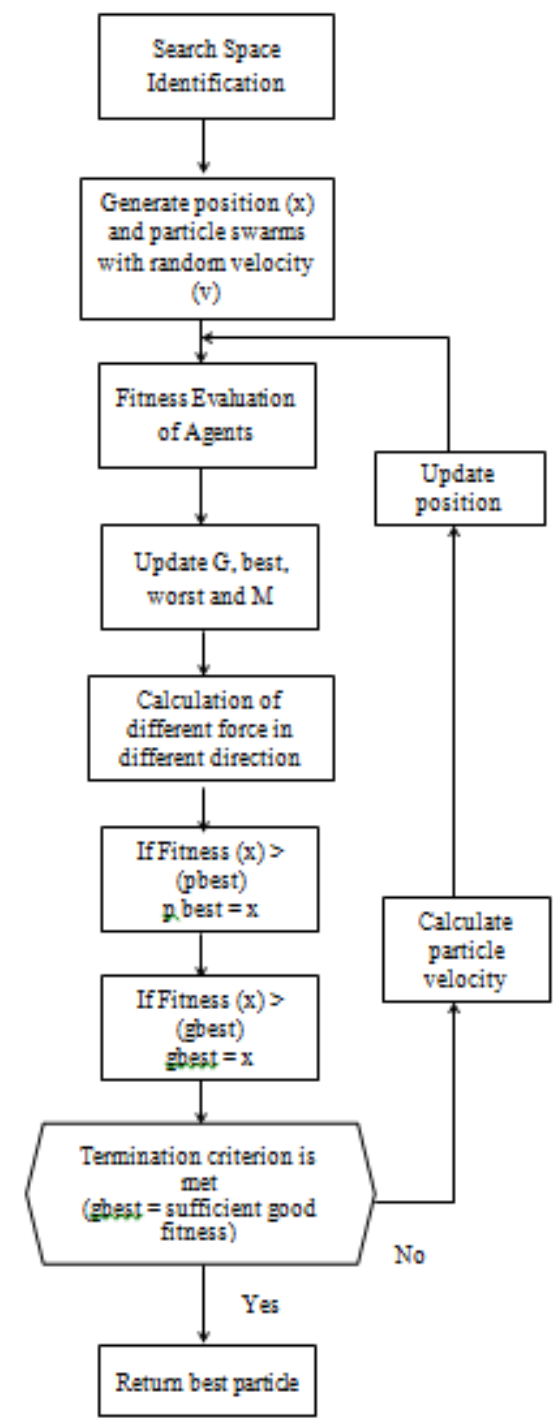

Fig 1 ANN training using Particle Swarm Optimization and Gravitational Search Algorithm

Numerically, the target capacity is defined as follows,

$$
\begin{aligned}
& E(X, P)=\min \sum_{s=1}^{S} P_{s}\left[\sum_{i=1}^{N} \sum_{t=1}^{H} F_{i}\left(P_{i, t}^{s}\right) X_{i, t}\right. \\
&\left.+\sum_{t=1}^{H}\left(C_{e n s} * E^{s} S_{t}^{s}+C_{r n s} * R_{N S}^{s}\right)\right] \\
&+\sum_{i=1}^{N} \sum_{t=1}^{H}\left[S_{i, t}\left(1-X_{i,(t-1)}\right)\right] X_{i, t}
\end{aligned}
$$

$\mathrm{F}_{\mathrm{i}}\left(\mathrm{P}_{\mathrm{i}, \mathrm{t}}^{\mathrm{s}}\right)$ is the thermal cost, typically spoken to as a quadratic capacity:

$$
F_{i}\left(P_{i, t}^{s}\right)=a_{i}+b_{i} P_{i, t}^{s}+c_{i}\left(P_{i, t}^{s}\right)^{2}
$$

The startup cost is used by the constant OFF time of the generators. 


$$
\mathrm{SU}_{\mathrm{i}, \mathrm{t}}= \begin{cases}\mathrm{HSU}_{\mathrm{i}, \mathrm{t}}, & \text { if } \mathrm{T}_{\mathrm{i}, \mathrm{t}}^{\mathrm{OFF}} \leq \mathrm{T}_{\mathrm{i}}^{\mathrm{DOWN}}+\mathrm{T}_{\mathrm{i}}^{\mathrm{COLD}} \\ \mathrm{CSU}_{\mathrm{i}, \mathrm{t},}, & \text { if } \mathrm{T}_{\mathrm{i}, \mathrm{t}}^{\mathrm{OFF}}>\mathrm{T}_{\mathrm{i}}^{\text {DOWN }}+\mathrm{T}_{\mathrm{i}}^{\text {COLD }}\end{cases}
$$

The following constraints are also defined.

- $\quad$ Power balance constraints

$$
\sum_{\mathrm{i}=1}^{\mathrm{N}} \mathrm{X}_{\mathrm{i}, \mathrm{t}} \mathrm{P}_{\mathrm{i}, \mathrm{t}}^{\mathrm{s}}+\mathrm{W}_{\mathrm{t}}^{\mathrm{s}}=\mathrm{D}_{\mathrm{t}}-\mathrm{ENS}_{\mathrm{t}}^{\mathrm{s}}
$$

- $\quad$ Spinning Reserve (SR) constraints

$$
\sum_{i=1}^{N} X_{i, t}\left[P_{i, \max }-P_{i, t}^{s}\right] \geq R_{t}^{s}-\operatorname{RNS}_{t}^{s}
$$

- $\quad$ Generation limit constraints

$$
\mathrm{P}_{\mathrm{i}, \min } \mathrm{X}_{\mathrm{i}, \mathrm{t}} \leq \mathrm{P}_{\mathrm{i}, \mathrm{t}}^{\mathrm{s}} \leq \mathrm{P}_{\mathrm{i}, \max } \mathrm{X}_{\mathrm{i}, \mathrm{t}}
$$

- $\quad$ Minimum uptime constraints

$$
\left(\mathrm{T}_{\mathrm{i}, \mathrm{t}}^{\mathrm{ON}}-\mathrm{T}_{\mathrm{i}}^{\mathrm{UP}}\right)\left(\mathrm{X}_{\mathrm{i},(\mathrm{t}-1)}-\mathrm{X}_{\mathrm{i}, \mathrm{t}}\right) \geq 0
$$

Where

$$
\mathrm{T}_{\mathrm{i}, \mathrm{t}}^{\mathrm{ON}}=\left(\mathrm{T}_{\mathrm{i},(\mathrm{t}-1)}^{\mathrm{ON}}+1\right) \mathrm{X}_{\mathrm{i}, \mathrm{t}}
$$

- $\quad$ Minimum downtime constraints

$$
\left(\mathrm{T}_{\mathrm{i}, \mathrm{t}}^{\text {OFF }}-\mathrm{T}_{\mathrm{i}}^{\text {DOWN }}\right)\left(\mathrm{X}_{\mathrm{i}, \mathrm{t}}-\mathrm{X}_{\mathrm{i},(\mathrm{t}-1)}\right) \geq 0
$$

Where

$$
\mathrm{T}_{\mathrm{i}, \mathrm{t}}^{\mathrm{OFF}}=\left(\mathrm{T}_{\mathrm{i},(\mathrm{t}-1)}^{\mathrm{OFF}}+1\right)\left(1-\mathrm{X}_{\mathrm{i}, \mathrm{t}}\right)
$$

In condition (8) and (10), the superscript ON and OFF demonstrate the status of the generators, while here and there represent the startup and shutdown of the generators minimum uptime.$T_{-}{ }^{i} \wedge \mathrm{UP}$ and minimum downtime $\mathrm{T} \_\mathrm{i} \wedge$ DOWN of the unit $\mathrm{i}$. When the unit is running, it ought not be killed right away. When the unit is de-dedicated, there is a base time before it tends to be recommitted.

Hybrid MM-Bee Colony algorithm calculation depends on social conduct of bumble bee provinces. It is a populace based pursuit system and is utilized as an enhancement device in illuminating complex, non-direct and non-curved advancement issues. Bumble bees share the data about area, amount and nature of nourishment source. This data sharing action can be utilized for unit duty issue. There are three kinds of bumble bees in a honey bee state. They are Onlooker honey bees, utilized honey bees and scout honey bees. Utilized honey bees search the areas of nourishment in parallel and educate to different honey bees by moving. Spectator honey bees assess the wellness and select the best arrangement among the arrangements given by all the utilized honey bees. Scout honey bees are utilized to locate the new arrangement.

In Hybrid MM-Bee Colony algorithm calculation issue's answers are spoken to by sustenance sources. Number of utilized honey bees is equivalent to the quantity of sustenance sources (arrangements). Each utilized honey bee is doled out to the one sustenance source. On achieving the source, the honey bee ascertains another arrangement and holds the best arrangement utilizing covetous determination system. At the point when an answer neglects to improve iteratively, it is dumped and supplanted by new sustenance source found by scout honey bee. Fig 2 shows the flowchart of Hybrid MM-Bee Colony algorithm based SCUC solution method.

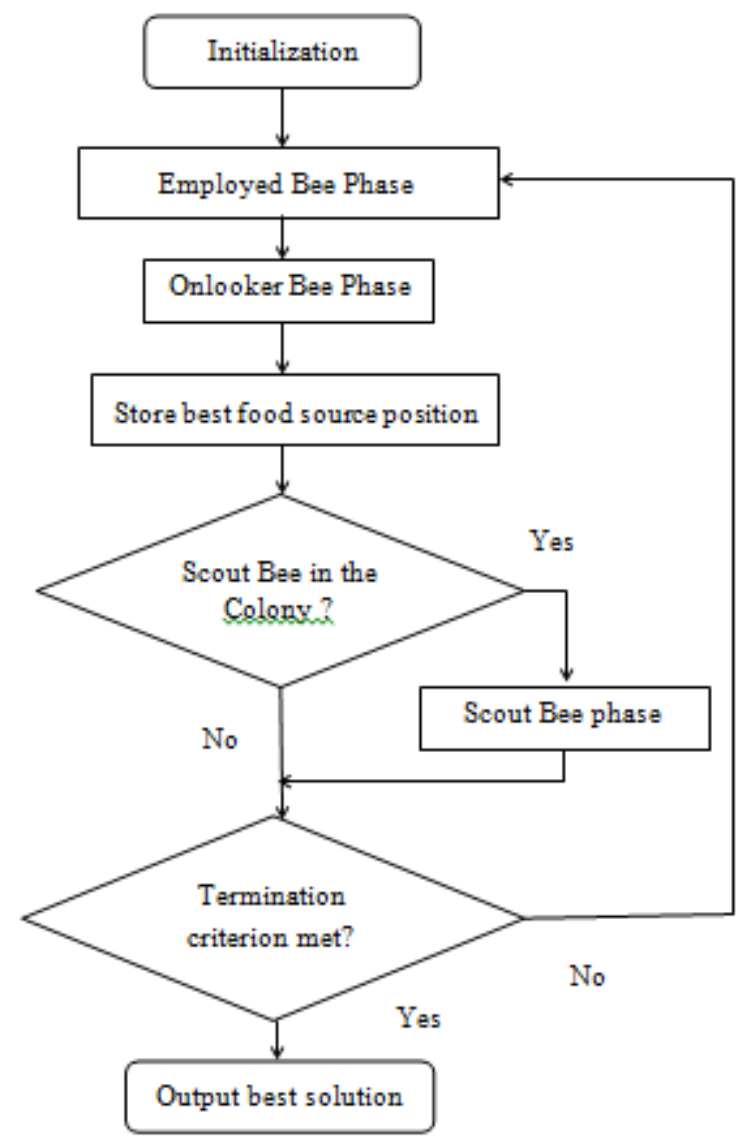

Fig 2 Flowchart of the Hybrid MM-Bee Colony algorithm -based solution method

\section{RESULTS}

\section{A.WIND POWER FORECASTING}

The numerical streamlining procedures based Memetic Algorithm is the quickest and amazing technique for preparing of moderate-sized feed-forward neural systems. The MM calculation attempts to limit the Mean Square Error (MSE) for example the exhibition capacity to be limited is type of a whole of squares. For every one of the Memetic Algorithm instructional courses, the loads and predispositions for info and concealed layers are spared and are used in the following instructional meeting iteratively until an agreeable reenactment result is gotten. With various info highlights and comparing focuses on, the system has been prepared more than once until it has accomplished some presentation criteria (satisfactory resilience, preparing time, and ages).

Fig 3 shows that forecasted wind power generation.

Published By: 
Hybrid Search Optimization Algorithms for the Security Constrained Unit Commitment Solution

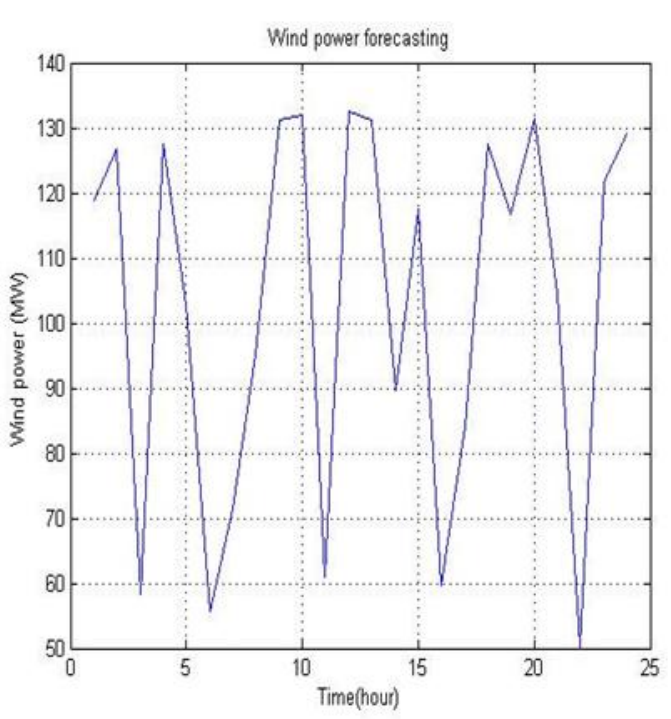

Fig.3 Forecasted wind power

\section{B. UNIT COMMITMENT}

Wind power forecasting is captured into the stochastic unit commitment approach. Hybrid MM-Bee Colony algorithm is used as optimization technique for this unit commitment problem. Input data for the Hybrid MM-Bee Colony algorithm includes thermal unit's constraints, parameters of each unit and spinning reserve. In this work 10 unit system is used. The installed generation capacity is $1662 \mathrm{MW}$, which is $10.8 \%$ higher than the peak load (1500 MW at Hour 12) capacity. The limit of the entered breeze homestead is thought to be $200 \mathrm{MW}$. The fundamental SR prerequisite is considered as $10 \%$ of the framework load. Extra save prerequisite can be added to remunerate the additional breeze vulnerabilities not caught by the created situations and the potential crises.

Table 1: 24 hours Load and SR profile data

\begin{tabular}{|l|l|l|l|l|l|l|l|l|}
\hline Hour & $\begin{array}{l}\text { Load } \\
(\mathrm{MW})\end{array}$ & $\begin{array}{l}\text { SR } \\
(\mathrm{MW})\end{array}$ & Hour & $\begin{array}{l}\text { Load } \\
(\mathrm{MW})\end{array}$ & $\begin{array}{l}\text { SR } \\
(\mathrm{MW})\end{array}$ & Hour & $\begin{array}{l}\text { Load } \\
(\mathrm{MW})\end{array}$ & $\begin{array}{l}\text { SR } \\
(\mathrm{MW})\end{array}$ \\
\hline 1 & 700 & 210 & 9 & 1300 & 197 & 17 & 1000 & 332 \\
\hline 2 & 750 & 160 & 10 & 1400 & 152 & 18 & 1100 & 232 \\
\hline 3 & 850 & 222 & 11 & 1450 & 157 & 19 & 1200 & 132 \\
\hline 4 & 950 & 122 & 12 & 1500 & 162 & 20 & 1400 & 152 \\
\hline 5 & 1000 & 202 & 13 & 1400 & 152 & 21 & 1300 & 197 \\
\hline 6 & 1100 & 232 & 14 & 1300 & 197 & 22 & 1100 & 137 \\
\hline 7 & 1150 & 182 & 15 & 1000 & 132 & 23 & 900 & 172 \\
\hline 8 & 1200 & 132 & 16 & 1050 & 282 & 24 & 800 & 110 \\
\hline
\end{tabular}

Table 2: 10 unit system profile data 1

\begin{tabular}{|l|l|l|l|l|l|}
\hline \multirow{2}{*}{ Parameters } & \multicolumn{5}{|c|}{ Units } \\
\cline { 2 - 6 } & \multicolumn{1}{|c|}{1} & \multicolumn{1}{|c|}{2} & \multicolumn{1}{|c|}{3} & \multicolumn{1}{c|}{4} & \multicolumn{1}{c|}{5} \\
\hline $\mathrm{a}_{\mathrm{i}}(\$ / \mathrm{h})$ & 1000 & 970 & 700 & 680 & 450 \\
\hline $\mathrm{b}_{\mathrm{i}}(\$ / \mathrm{MWh})$ & 16.19 & 17.26 & 16.6 & 16.5 & 19.7 \\
\hline $\mathrm{c}_{\mathrm{i}}(\$ / \mathrm{MW} 2 \mathrm{~h})$ & 0.00048 & 0.00031 & 0.002 & 0.0021 & 0.00398 \\
\hline $\mathrm{P}_{\mathrm{i}, \max }(\mathrm{MW})$ & 456 & 456 & 131 & 131 & 164 \\
\hline $\mathrm{P}_{\mathrm{i}, \min }(\mathrm{MW})$ & 140 & 140 & 20 & 20 & 25 \\
\hline $\mathrm{T}_{\mathrm{i}, 0}(\mathrm{~h})$ & 8 & 8 & -5 & -5 & -6 \\
\hline $\mathrm{T}_{\mathrm{i}}{ }^{\text {on }}(\mathrm{h})$ & 8 & 8 & 5 & 5 & 6 \\
\hline $\mathrm{T}_{\mathrm{i}}{ }^{\text {off }}(\mathrm{h})$ & 8 & 8 & 5 & 5 & 6 \\
\hline $\mathrm{HSC}_{\mathrm{i}}(\$)$ & 4500 & 5000 & 560 & 560 & 890 \\
\hline $\mathrm{CSC}_{\mathrm{i}}(\$)$ & 9000 & 10000 & 1200 & 1020 & 1700 \\
\hline $\mathrm{T}_{\mathrm{i}}^{\text {cold }}(\mathrm{h})$ & 5 & 5 & 4 & 4 & 4 \\
\hline $\mathrm{FLAC}^{(\$)}$ & 18.61 & 19.53 & 22.24 & 22.01 & 23.12 \\
\hline
\end{tabular}

Table 3: 10 unit system profile data 1

\begin{tabular}{|c|c|c|c|c|c|}
\hline \multirow{2}{*}{ Parameters } & \multicolumn{5}{|c|}{ Units } \\
\hline & 6 & 7 & 8 & 9 & 10 \\
\hline$a_{i}(\$ / \mathrm{h})$ & 370 & 480 & 660 & 665 & 670 \\
\hline$b_{i}(\$ / \mathrm{MWh})$ & 22.26 & 27.74 & 25.92 & 27.27 & 27.79 \\
\hline$c_{i}\left(\$ / \mathrm{MW}^{2} \mathrm{~h}\right)$ & 0.0071 & 0.0007 & 0.0041 & 0.0022 & 0.0017 \\
\hline$P_{i, \max }(M W)$ & 80 & 84 & 56 & 55 & 55 \\
\hline$P_{i, \min }(M W)$ & 20 & 25 & 10 & 10 & 10 \\
\hline $\mathrm{T}_{\mathrm{i}, 0}(\mathrm{~h})$ & -3 & -3 & -1 & -1 & -1 \\
\hline $\mathrm{T}_{\mathrm{i}^{\text {on }}}^{\text {on }}(\mathrm{h})$ & 3 & 3 & 1 & 1 & 1 \\
\hline $\mathrm{T}_{\mathrm{i}}{ }^{\text {off }}(\mathrm{h})$ & 3 & 3 & 1 & 1 & 1 \\
\hline $\mathrm{HSC}_{\mathrm{i}}(\$)$ & 180 & 270 & 30 & 30 & 30 \\
\hline $\operatorname{CSC}_{i}(\$)$ & 350 & 525 & 60 & 60 & 60 \\
\hline $\mathrm{T}_{\mathrm{i}}^{\text {cold }}(\mathrm{h})$ & 2 & 2 & 0 & 0 & 0 \\
\hline FLAC (\$) & 27.45 & 33.45 & 38.14 & 39.48 & 40.06 \\
\hline
\end{tabular}

Table 4 Total generation cost data 1

\begin{tabular}{|l|l|l|l|l|l|l|}
\hline \multirow{2}{*}{ Units } & \multicolumn{7}{|c|}{ Hours } \\
\cline { 2 - 7 } & 1 & 2 & 3 & 4 & 5 & 6 \\
\hline 1 & 387.8822 & 0 & 451.8514 & 452.6628 & 397.8855 & 380.1736 \\
\hline 2 & 0 & 450.202 & 0 & 0 & 268.8855 & 320.1736 \\
\hline 3 & 0 & 0 & 0 & 0 & 0 & 0 \\
\hline 4 & 0 & 0 & 0 & 0 & 0 & 90.17357 \\
\hline 5 & 0 & 0 & 143.8514 & 150.6628 & 0 & 0 \\
\hline 6 & 31.8822 & 0 & 0 & 0 & 0 & 0 \\
\hline 7 & 0 & 0 & 0 & 0 & 0 & 0 \\
\hline 8 & 0 & 0 & 0 & 0 & 0 & 0 \\
\hline 9 & 0 & 0 & 0 & 0 & 0 & 0 \\
\hline 10 & 0 & 0 & 0 & 0 & 0 & 0 \\
\hline SUC & 0 & 0 & 0 & 0 & 0 & 560 \\
\hline $\begin{array}{l}\text { Fuel } \\
\text { cost }\end{array}$ & 8438.965 & 8803.319 & 11779.71 & 1193536 & 13151.13 & 15937.3 \\
\hline $\begin{array}{l}\text { Total } \\
\text { cost(\$) }\end{array}$ & 8438.965 & 8803.319 & 11779.71 & 1193536 & 13151.13 & 16497.3 \\
\hline
\end{tabular}

Table 5 Total generation cost data 2 


\begin{tabular}{|l|l|l|l|l|l|l|}
\hline \multirow{2}{*}{ Units } & \multicolumn{7}{|c|}{ Hours } \\
\cline { 2 - 7 } & 7 & \multicolumn{1}{|c|}{8} & \multicolumn{1}{c|}{9} & \multicolumn{1}{c|}{10} & \multicolumn{1}{c|}{11} & 12 \\
\hline 1 & 329.0353 & 410.9615 & 430.3438 & 420.0398 & 410.57 & 379.866 \\
\hline 2 & 373.0353 & 382.9615 & 438.3438 & 417.0398 & 371.57 & 423.866 \\
\hline 3 & 111.0353 & 0 & 0 & 0 & 0 & 0 \\
\hline 4 & 0 & 0 & 0 & 0 & 0 & 0 \\
\hline 5 & 0 & 0 & 0 & 108.0398 & 0 & 0 \\
\hline 6 & 0 & 0 & 0 & 0 & 48.57 & 59.86601 \\
\hline 7 & 0 & 0 & 0 & 0 & 0 & 0 \\
\hline 8 & 0 & 0 & 0 & 0 & 0 & 0 \\
\hline 9 & 0 & 0 & 0 & 0 & 0 & 11.86601 \\
\hline 10 & 0 & 0 & 0 & 0 & 0 & 0 \\
\hline SUC & 0 & 0 & 0 & 900 & 0 & 60 \\
\hline $\begin{array}{l}\text { Fuel } \\
\text { cost }\end{array}$ & 16398.62 & 15359.91 & 16651.54 & 18732 & 16622.1 & 18277.95 \\
\hline $\begin{array}{l}\text { Total } \\
\text { cost(\$) }\end{array}$ & 16398.62 & 15359.91 & 16651.54 & 19632 & 16622.1 & 18337.95 \\
\hline
\end{tabular}

Table 6 Total generation cost data 3

\begin{tabular}{|l|l|l|l|l|l|l|}
\hline \multirow{2}{*}{ Units } & \multicolumn{7}{|c|}{ Hours } \\
\cline { 2 - 7 } & 13 & 14 & 15 & 16 & 17 & 18 \\
\hline 1 & 410.6852 & 455 & 392.7426 & 365.177 & 431.7949 & 439.0302 \\
\hline 2 & 433.6852 & 455 & 379.7426 & 383.177 & 252.7949 & 371.0302 \\
\hline 3 & 0 & 0 & 0 & 0 & 0 & 0 \\
\hline 4 & 0 & 0 & 0 & 0 & 0 & 0 \\
\hline 5 & 0 & 0 & 0 & 0 & 0 & 0 \\
\hline 6 & 58.68516 & 0 & 32.74264 & 0 & 0 & 0 \\
\hline 7 & 0 & 0 & 0 & 0 & 0 & 0 \\
\hline 8 & 0 & 0 & 0 & 0 & 0 & 0 \\
\hline 9 & 0 & 0 & 0 & 0 & 0 & 0 \\
\hline 10 & 0 & 0 & 0 & 0 & 0 & 0 \\
\hline SUC & 0 & 0 & 340 & 0 & 0 & 0 \\
\hline $\begin{array}{l}\text { Fuel } \\
\text { cost }\end{array}$ & 1794451 & 173533 & 16108.09 & 1460538 & 13433.3 & 15617.07 \\
\hline $\begin{array}{l}\text { Total } \\
\text { cost(\$) }\end{array}$ & 17944.51 & 173533 & 16448.09 & 1460538 & 13433.3 & 15617.07 \\
\hline
\end{tabular}

Table 7 Total generation cost data 4

\begin{tabular}{|l|l|l|l|l|l|l|}
\hline \multirow{2}{*}{ Units } & \multicolumn{7}{|c|}{ Hours } \\
\cline { 2 - 7 } & \multicolumn{1}{|c|}{19} & \multicolumn{1}{|c|}{20} & \multicolumn{1}{|c|}{21} & \multicolumn{1}{|c|}{22} & \multicolumn{1}{|c|}{23} & \multicolumn{1}{c|}{24} \\
\hline 1 & 413.4306 & 399.8188 & 453.0953 & 390.185 & 447.6502 & 424.0966 \\
\hline 2 & 353.4306 & 437.8188 & 441.0953 & 342.185 & 0 & 0 \\
\hline 3 & 0 & 0 & 0 & 0 & 0 & 62.09659 \\
\hline 4 & 116.4306 & 107.8188 & 0 & 0 & 109.6502 & 0 \\
\hline 5 & 0 & 0 & 0 & 0 & 0 & 0 \\
\hline 6 & 0 & 0 & 0 & 0 & 0 & 0 \\
\hline 7 & 0 & 0 & 0 & 0 & 0 & 0 \\
\hline 8 & 0 & 0 & 0 & 0 & 0 & 0 \\
\hline 9 & 0 & 0 & 0 & 0 & 0 & 0 \\
\hline 10 & 0 & 0 & 0 & 0 & 0 & 0 \\
\hline SUC & 1120 & 0 & 0 & 0 & 0 & 0 \\
\hline $\begin{array}{l}\text { Fuel } \\
\text { cost }\end{array}$ & 1751399 & 1861939 & 17077.77 & 14302.58 & 10858.12 & 9690.971 \\
\hline $\begin{array}{l}\text { Total } \\
\text { cost(\$) }\end{array}$ & 1863399 & 1861939 & 17077.77 & 14302.58 & 10858.12 & 9690.971 \\
\hline
\end{tabular}

Table 1 shows SR and load forecasting data for 24 hours. Table 2 and Table 3 shows the 10 unit system data for thermal generators. As shown in Table 1, Table 2 and Table 3 , a ten-unit system data and load demands are given [2]. Cost is expressed in dollars (\$). HSCi and CSCi denote Hot Startup Cost and Cold Startup Cost of unit i. The modified UC test system [1] and [14] scenario is added with wind power generation uncertainties.. Table 4, Table 5, Table 6 and Table 7 shows the total generation cost of 10 unit thermal test system for the next 24 hours using $\mathrm{ABC}$ algorithm. Table 8 shows the SCUC problem solution using ABC algorithm.

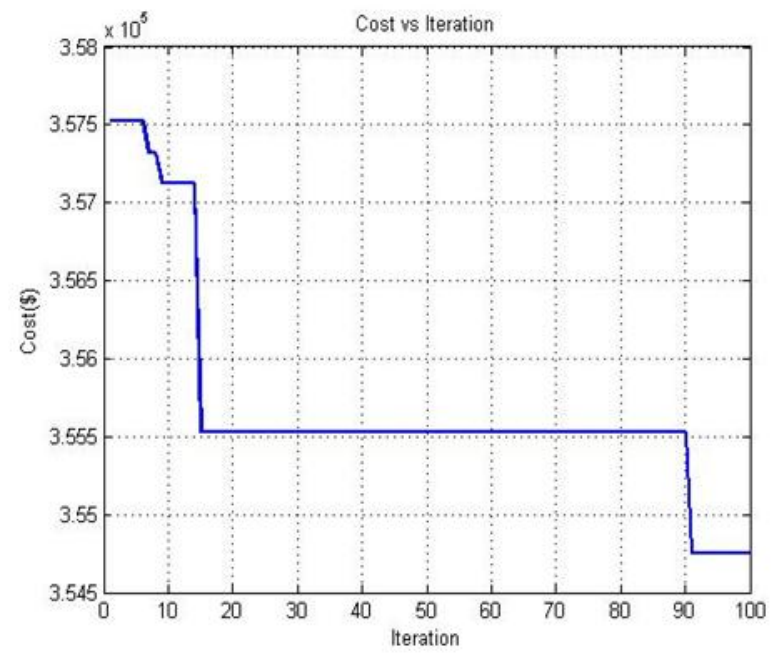

Fig 4 Cost Vs. Iteration using Bee Colony algorithm Table 8 SCUC solution using Bee Colony algorithm

\begin{tabular}{|c|c|c|c|c|c|c|c|c|c|c|}
\hline \multirow{2}{*}{ Hours } & \multicolumn{10}{|c|}{ Unit number } \\
\cline { 2 - 12 } & $\mathbf{1}$ & $\mathbf{2}$ & $\mathbf{3}$ & $\mathbf{4}$ & $\mathbf{5}$ & $\mathbf{6}$ & $\mathbf{7}$ & $\mathbf{8}$ & $\mathbf{9}$ & $\mathbf{1 0}$ \\
\hline $\mathbf{1}$ & 1 & 0 & 0 & 0 & 0 & 1 & 0 & 0 & 0 & 0 \\
\hline $\mathbf{2}$ & 0 & 1 & 0 & 0 & 0 & 0 & 0 & 0 & 0 & 0 \\
\hline $\mathbf{3}$ & 1 & 0 & 0 & 0 & 1 & 0 & 0 & 0 & 0 & 0 \\
\hline $\mathbf{4}$ & 1 & 0 & 0 & 0 & 1 & 0 & 0 & 0 & 0 & 0 \\
\hline $\mathbf{5}$ & 1 & 1 & 0 & 0 & 0 & 0 & 0 & 0 & 0 & 0 \\
\hline $\mathbf{6}$ & 1 & 1 & 0 & 1 & 0 & 0 & 0 & 0 & 0 & 0 \\
\hline $\mathbf{7}$ & 1 & 1 & 1 & 0 & 0 & 0 & 0 & 0 & 0 & 0 \\
\hline $\mathbf{8}$ & 1 & 1 & 0 & 0 & 0 & 0 & 0 & 0 & 0 & 0 \\
\hline $\mathbf{9}$ & 1 & 1 & 0 & 0 & 0 & 0 & 0 & 0 & 0 & 0 \\
\hline $\mathbf{1 0}$ & 1 & 1 & 0 & 0 & 1 & 0 & 0 & 0 & 0 & 0 \\
\hline $\mathbf{1 1}$ & 1 & 1 & 0 & 0 & 0 & 1 & 0 & 0 & 0 & 0 \\
\hline $\mathbf{1 2}$ & 1 & 1 & 0 & 0 & 0 & 1 & 0 & 0 & 1 & 0 \\
\hline $\mathbf{1 3}$ & 1 & 1 & 0 & 0 & 0 & 1 & 0 & 0 & 0 & 0 \\
\hline $\mathbf{1 4}$ & 1 & 1 & 0 & 0 & 0 & 0 & 0 & 0 & 0 & 0 \\
\hline $\mathbf{1 5}$ & 1 & 1 & 0 & 0 & 0 & 1 & 0 & 0 & 0 & 0 \\
\hline $\mathbf{1 6}$ & 1 & 1 & 0 & 0 & 0 & 0 & 0 & 0 & 0 & 0 \\
\hline $\mathbf{1 7}$ & 1 & 1 & 0 & 0 & 0 & 0 & 0 & 0 & 0 & 0 \\
\hline $\mathbf{1 8}$ & 1 & 1 & 0 & 0 & 0 & 0 & 0 & 0 & 0 & 0 \\
\hline $\mathbf{1 9}$ & 1 & 1 & 0 & 1 & 0 & 0 & 0 & 0 & 0 & 0 \\
\hline $\mathbf{2 0}$ & 1 & 1 & 0 & 1 & 0 & 0 & 0 & 0 & 0 & 0 \\
\hline $\mathbf{2 1}$ & 1 & 1 & 0 & 0 & 0 & 0 & 0 & 0 & 0 & 0 \\
\hline $\mathbf{2 2}$ & 1 & 1 & 0 & 0 & 0 & 0 & 0 & 0 & 0 & 0 \\
\hline $\mathbf{2 3}$ & 1 & 0 & 0 & 1 & 0 & 0 & 0 & 0 & 0 & 0 \\
\hline $\mathbf{2 4}$ & 1 & 0 & 1 & 0 & 0 & 0 & 0 & 0 & 0 & 0 \\
\hline
\end{tabular}




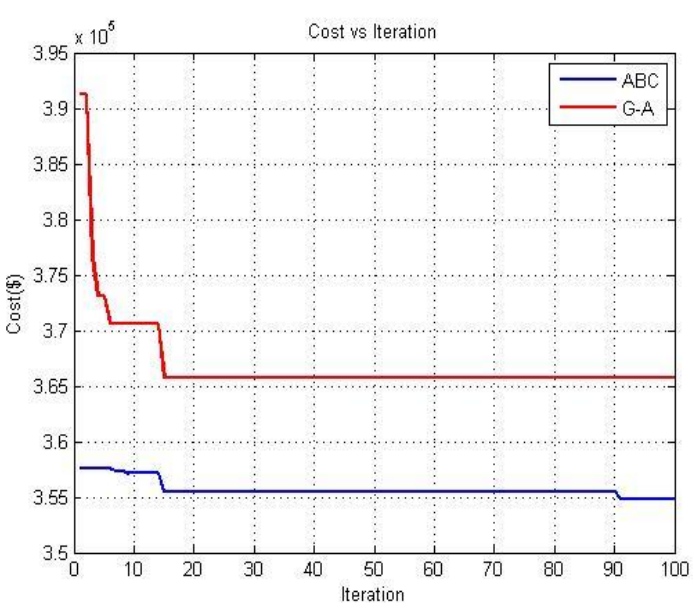

Fig 5 Cost Vs. Iteration using GA and ABC algorithm

The scheduled UC generation cost is based on the dayahead UC decision and the different wind power forecasts he expense of wind age is viewed as zero. At that point the bigger extent of wind control entrance will prompt a less generation cost, and the other way around. A portion of the key parameters affect the nature of arrangements. For instance, expanding the quantity of emphases requires a more drawn out calculation time and a tradeoff is in this manner required. Fig 4 shows that total generation cost can be reduced by increasing the number of iterations. Fig 5 demonstrates that ideal arrangement can be acquired utilizing Hybrid MM-Bee Colony algorithm calculation as opposed to GA.

\section{IV.CONCLUSION AND FUTURE SCOPE}

A nonparametric and proposed hybrid Particle Swarm Optimization and Gravitational Search Algorithm based LUBE strategy is utilized to develop Memetic algorithm based PIs. Wind power gauge vulnerabilities are spoken to by a rundown of PIs. Wind vulnerabilities are considered as a stochastic procedure through the created situations. A stochastic SCUC model is assembled and the wind situations are consolidated into this model. Hybrid MM-Bee Colony algorithm calculation is utilized to take care of the stochastic SCUC issue. Results show that optimum unit commitment solution can be obtained using Hybrid MMBee Colony algorithm rather than GA.

\section{REFERENCES}

1. C.P. Cheng, C.W. Liu, and C.-C. Liu (2000), "Unit commitment by Lagrangian relaxation and genetic algorithms," IEEE Trans. Power Syst., vol. 15, no. 2, pp. 707-714.

2. HaoQuan, DiptiSrinivasan and Abbas Khosravi (2014)," Incorporating wind power forecast uncertainties into stochastic unit commitment using neural network-based prediction intervals." IEEE Trans. Neural Netw. Learn. Syst., Vol.26, Issue. 9.

3. R. Jiang, J. Wang, and Y. Guan (2012), "Robust unit commitment with wind power and pumped storage hydro," IEEE Trans. Power Syst., vol. 27, no. 2, pp. 800-810.

4. A. Kazarlis, A. G. Bakirtzis, and V. Petridis (1996), "A genetic algorithm solution to the unit commitment problem," IEEE Trans. Power Syst., vol. 11, no. 1, pp. 83-92.

5. T. Logenthiran and D. Srinivasan (2010), "Particle swarm optimization for unit commitment problem," in Proc. IEEE 11th Int. Conf. Probab. MethodsAppl. Power Syst. (PMAPS), pp. 642-647.

6. D. Srinivasan and J. Chazelas (2004), "A priority list-based evolutionary algorithm to solve large scale unit commitment problem," in Proc. Int. Conf. Power Syst. Technol. (PowerCon), vol. 2, pp. 1746-1751.

7. A. Sturt and G. Strbac (2012), "Efficient stochastic scheduling for simulation of wind-integrated power systems," IEEE Trans. Power Syst., vol. 27, no. 1, pp. 323-334.

8. K. S. Swarup and S. Yamashiro (2002), "Unit commitment solution methodology using genetic algorithm," IEEE Trans. Power Syst., vol. 17, no.1, pp. 87-91.

9. B. C. Ummels, M. Gibescu, E. Pelgrum, W. L. Kling, and A. J. Brand (2007), "Impacts of wind power on thermal generation unit commitment and dispatch," IEEE Trans. Energy Convers., vol. 22, no. 1, pp. 44-51.

10. J. Wang, M. Shahidehpour, and Z. Li (2008), "Security-constrained unit commitment with volatile wind power generation," IEEE Trans. Power Syst., vol. 23, no. 3, pp. 1319-1327.

11. Asis Kumar Tripathy, SuvenduMohapatra, ShradhanandaBeura and GunanidhiPradhan (2011), "Weather Forecasting using ANN and PSO" International Journal of Scientific \& Engineering Research Volume 2, Issue 7.

12. Khosravi. A, Nahavandi. S, Creighton. D and Atiya. A.F (2011), "Comprehensive review of neural network-based prediction intervals and new advances," IEEE Trans. Neural Netw., vol. 22, no. 9, pp. 1341-1356.

13. Ma. X.Y, Sun. Y.Z and Fang. H.L (2013), "Scenario generation of wind power based on statistical uncertainty and variability," IEEE Trans. Sustainable Energy, vol. 4, no. 4, pp. 894-904.

14. Ongsakul. W and Petcharaks. N (2004), "Unit commitment by enhanced adaptive Lagrangian relaxation," IEEE Trans. Power Syst., vol. 19 , no. 1, pp. 620-628.

15. Ortega-Vazquez. M.A and Kirschen.D.S (2009), "Estimating the spinning reserve requirements in systems with significant wind power generation penetration," IEEE Trans. Power Syst., vol. 24, no. 1, pp. 114-124.

16. Sree Renga Raja. T, Marimuth N.S. and Albert Sing.N (2007),"A novel neural network for economic load dispatch with environmental constraints" International Journal of Electrical and power Engineering1(1):7-12

17. Vigneswari. T and Maluk Mohamed. M.A (2014)," Optimal Grid Scheduling Using Improved Artificial Bee Colony Algorithm" International Journal of Computer, Electrical, Automation, Control and Information Engineering Vol: 8, No:11.

18. Zielinski. K and Laur. R (2006), "Constrained single-objective optimization using particle swarm optimization," in Proc. IEEE Congr. Evol. Comput. (CEC), pp. 443-450. 